\title{
O Professor Waldemar Ferreira consagrado Professor emérito.
}

Realizou-se na manhã de 3 de abril de 1956, na sala João Mendes Júnior, da Faculdade de Direito da Universidade de São Paulo, a solenidade da abertura dos cursos jurídicos. Pronunciou a aula inaugural o Professor GroffreDo Telles Júnior, catedrático de Introdução à Ciência do Direito, que teve por têma - As fontes do Direito e a representação política.

Antes de proferida essa aula, em sessão solene da Congregação, presidida pelo Professor Alvino LIMA, vice-diretor da Faculdade de Direito em exercício, êste convidou os Professôres Sampaio Dória, Braz Arruda e Honório MonTEIro para, em comissão, introduzirem na sala o Professor Waldemar Ferreira, que havia sido aposentado compulsòriamente, por decreto do Presidente da República, de 26 de março de 1956, afim de receber o título de Professor Emérito, que lhe havia sido conferido pela Egrégia Congregação.

A seguir deu a palavra ao Professor Honório Monteiro, que proferiu o seguinte discurso:

\section{Discurso do professor Honório Monteiro.}

"Reabrem-se hoje, festivos como sempre, os cursos jurídicos de nossa Academia e, para maior realce da solenidade, a Congregação da Faculdade de Direito resolveu demonstrar, de público e solenemente, seu alto apreço a 
um dos mais ilustres de seus membros, o professor Waldemar Ferreira, conferindo-lhe o titulo de "Professor Emérito", na ocasião em quê, por imperativo constitucional, afasta-se êle da vida efetiva, da regência da cátedra de Direito Comercial que, com excepcional brilho, por mais de trinta anos, regeu e nela doutrinou.

Tocou-me, por designação de meus doutos colegas, a desvancedora missão de saudá-lo. Essa incumbência é particularmente grata ao meu coração de discípulo e de companheiro da mesma cátedra. Tôda a minha vida de estudioso do direito está reiteradamente vinculada ao consagrado e de todos nós querido mestre.

Lá pelos idos de 1917, ao tempo em que a carta de solicitador se obtinha mediante exame perante o Tribunal de Justiça, meu examinador foi o professor WaLdemar Ferreira, em cujo escritório, já solicitador, iniciei a prática da advocacia e recebi as primeiras lições atinentes à profíssão.

De Direito Comercial foi êle o meu mestre e o incentivador á especialização.

Volvidos anos, em 1932, já livre-docente, eu iniciei o magistério universitário substituindo o prof. WaIdemar FerREIRA no ensino de Direito Comercial á turma de que fazia parte Ruy Martins Ferreira, seu filho.

Nomeado catedrático, foi ainda o mestre quem me deu posse, substituindo o diretor efetivo.

Como vêm, tinha que ser eu o designado para saudar o mestre, no momento em que a Faculdade lhe confere o título de "Professor Emérito".

Outros dêle poderão dizer melhor e com mais brilho, nịnguém, porém, relevem-me, poderia juntar á saudação, maior afeto e gratidão.

Quem estuda a carreira sempre ascendente do mestre verificará, na variada ação em que se desdobra o curso de sua profícua existência, a constância de uma vontade nunca esmorecida, temperada sempre pelas mais puras virtudes 


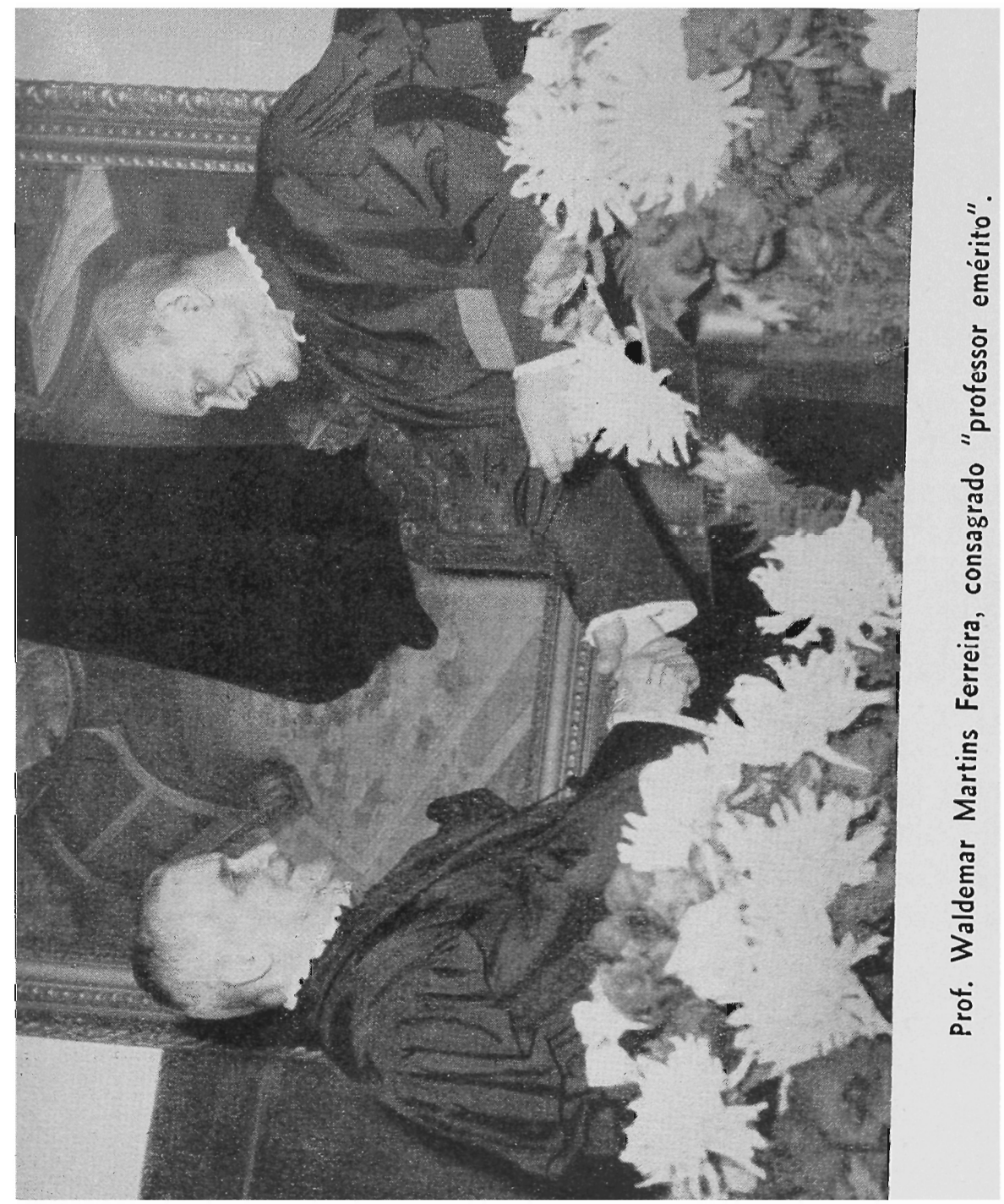


morais e cívicas e norteada por uma aguda inteligência, a serviço dos melhores atributos humanos de cultura, de operosidade, valor cívico e inteiresa moral, que exornam sua personalidade.

Por isso mesmo, sob qualquer prisma por que se cncare a vida do professor Waldemar Ferreira, ela se projeta sempre como paradígma.

Do cidadão, do homem público, do advogado, do professor, outros já disseram, com engenho e justeza.

Quero eu, nesta oportunidade, considerar a projeção do mestre através da sua obra de comercialista.

A rigor, o Direito Comercial, versado em língua portuguêsa, pode ser dividido no tempo, em três fases, assinaladas por três marcos culminantes.

Numa primeira fase, antes da promulgação do Código do Comércio, pontificaram dois vultos egrégios - o baiano José da Silva Lisboa - Visconde de Cairu', e o português José Ferreira Borges.

Silva Lisboa legou-nos os "Princípios de Direito Mercantil $e$ Leis de Marinha", a primeira construção jurídica sôbre Direito Comercial, em português. Ferreira Borges, além das "Instituições de Direito Cambial Português" e do "Dicionário Jurídico Comercial", redigiu o Projeto do primeiro Código Comercial Português. "Silva Lisboa e FERreira Borges, disse Carvalho de Mendonça, escreveram na vigência das mesmas leis e sob a influência das mesmas idéias, enxugaram as penas quase ao mesmo tempo. $O$ fulgor dos seus livros mantêm-se ainda nos nossos próprios dias, porque registraram com admirável cunho teórico em monografias separadas o Direito Comercial e o Marítimo do seu tempo, e, no plano lógico, que seguiram, simplificaram a confusão que os envolvia e, assim, firmaram um marco histórico, na ciência jurídica brasileira e portuguêsa"

A segunda fase da literatura jurídica sôbre Direito Comercial, culmina e se representa pela figura de CarvalHo DE MendonçA. 
O Código Comercial de 1850, originário de projeto de autoria de quatro comerciantes e um magistrado, não provocou, durante largo tempo, nenhum trabalho de exposição sistemática do Direito Comercial.

Carvalho de Mendonça, porém, como proclamam todos, num esfôrço impar, conseguiu sistematizar o nosso Direito Mercantil, e legar ao Brasil obra de acentuado cunho nacional, pois a doutrina que a estrutura, haurida embora nos grandes mestres estrangeiros, foi moldada na fôrça de nossas tradições jurídicas, quanto nas diretrizes de nossas leis e o direito vivo declarado pelos nossos juízes.

Por isso mesmo foi êle consagrado como o criador e sistematizador do Direito Comercial brasileiro, ao término de sua obra.

Mas a êsse tempo o professor Waldemar Ferreira já vinha e de há muito impondo-se ao conceito de todos como jurista e exímio cultor do Direito Comercial.

A seu respeito dizia Carvalho de Mendonça, em 1919, em apreciação crítica aos seus Estudos de Direito Comercial:

“Não tem passado despercebido os recentes estudos sôbre matéria comercial apresentados por uma plêiade de jovens notáveis pelo apuro do trabalho e pela louvável preocupação de manter a tradição do direito nacional. Entre os lidadores nessa obra patriótica, concorrendo para aperfeiçoar o nosso direito comercial, um dos que mais se distinguem é o dr. Walnemar Ferreira, que reune agora, nêste volume, os brilhantes escritos bastantemente conhecidos e apreciados no nosso meio jurídico. Não se trata de um livro escrito como outros livros, mas de uma obra originai, recomendável pelo profundo conhecimento revelado pelo autor, das nossas leis comerciais e dos principios científicos que as informam, pelos conceitos assentados, com seguranȩa é simplicidade e ainda pela exposição amena, sempre em boa linguagem" 
Todos os dominios do direito comercial, terrestre e marítimo, mereceram, dêsse infatigável trabalhador, o Professor Waldemar Ferreira, o carinho de um trabalho que contìnuadamente foi produzindo para enriquecimento da extensa bibliografia de suas obras.

O curso ministrado nesta casa, quando ainda livre-docente, em substituição ao professor OCTÁvio Mendes, deu motivo á publicação das respectivas lições, em dois volumes, sob a denominação - Curso de Direito Comercial.

Ausente da Patria, em 1932, valeu-se o mestre, que não para, do exilio, para enriquecer a literatura jurídica brasileira de mais um trabalho - As Diretrizes do Direito Mercantil Brasileiro - reunião das conferências proferidas na Universidade de Lisboa.

Nessa oportunidade, em Portugal, durante o exílio, pelos seus trabalhos sôbre direito comercial, foi o mestre consagrado, pelos juristas portuguêses - conspícuo comercialista - e, ao mesmo tempo concitado solenemente pela palavra do professor BARBosa DE MAGAlHÃEs a escrever um grande tratado de direito comercial "para definitiva consagração de seu nome, dizia, e para grande proveito de todos nós".

O professor Waldemar Ferreira não ficou indiferente ao convite dos mestres portuguêses. De retôrno à Patria iniciou, logo em 1934 a publicação do "Tratado de Direito Mercantil Brasileiro", que, em razão da instabilidade legislativa, durante o regime ditatorial, resolveu interromper no terceiro volume.

Eis como, sôbre esta obra, apenas iniciada, se pronunciou o professor Raymundo Fernandez, da Faculdade de Direito da Universidade de Buenos Aires: "obra extraordinária, que em meu conceito iguala e supera a êsse monumento da literatura jurídica de seu país que é o Tratado de Direito Comercial Brasileiro de José Xavier Carvalho DE Mendonça. Felicito-o sinceramente, estimado doutor, e com tôda efusão, porque seu trabalho é magnífico; e unido à 
sua multipla e substanciosa produção jurídica, em sua quase totalidade sôbre direito mercantil, revela-o como o primeiro comercialista brasileiro da atualidade".

Mas a capacidade produtora do mestre é incomum. Como disse Gudesteu Pires, "tem o privilégio de ultrapassar os limites do tempo ou as contingências da capacidade mental de trabalho".

Se o "Tratado ficara interrompido, of ereceu-nos o mestre, de imediato e como compensação, as Instituições de Direito Comercial", em cinco volumes, e que êle anunciou como sendo um "curso sumário e sistemático, de cunho didático"

Trata-se, porém, de trabalho pensado e meditado, de soberbo manancial de conhecimentos jurídicos.

O professor Eduardo Couture, da Universidade de Montevideu, teve oportunidade de dizer, sôbre a pessoa do mestre apreciando essa obra: "A um livro de Instituições não se chega senão depois de um largo processo de preparação. Ainda que pareça exagero, é mais fácil escrever um Tratado que umas Instituições. No primeiro encontram-se tôdas as matérias; no segundo devem figurar os melhores materiais. A seleção, a condensação e a limitação, eis os grandes méritos de uma obra de tal índole, á qual não pode atingir um professor senão depois de árduas etapas de preparação e de estudos".

Outro professor, também da Universidade de Montevideu, o professor Perez Fontana, a propósito da publicação da segunda edição das Instituições proclama "en el momento actual es el más grande de los comercialistas brasileños".

E Mario Patond, professor de Direito Comercial da Faculdade de Direito de Pávia, depois de se referir a outros juristas brasileiros, acrescenta: "Entre os continuadores desta ilustre tradição de juristas, figura o autor desta obra que se intitula modestamente Instituições de Direito 
Comercial, embora pela amplitude do desenvolvimento e profundeza da exposição, a obra se apresente como verdadeiro e próprio tratado".

$\mathrm{E}$ mais não será preciso diser para pôr em evidência a personalidade do professor Waldemar Ferreira como expressão atual do comercialista mais autorizado e de maior projeção nas letras jurídicas nacionais.

Sucedendo, pela primazia, a Carvalho de Mendonça, não lhe desmereceu a obra, antes completou, com seguro e cunho próprio, a sistematização de nosso direito comercial.

Escrevendo em período tumultuário da humanidade, ou seja, de profundas e permanentes perturbações econômicas e largas comoções sociais, contrastante com a serenidade da época em que Carval ho de Mendonça escreveu, avulta a ação discíplinadora do mestre, ao plasmar os novos institutos e ao adaptar os existentes ás contingências das condições econômicas, políticas e sociais contemporâneas, que pressionam a atividade mercantil e repercutem na sua disciplina, sem se perder, porém, no emaranhado ou no exagero de doutrinas exóticas, incompatíveis com a tradição de nosso direito e a sistemática de nossas leis.

Eis aí porque o mestre personifica a fase atual da ciência jurídica comercial brasileira.

Professor Waldemar Ferrerra:

Conferindo-lhe o título de Professor Emérito, a mais. conspícua e dignificante das honras de que dispõe, quer a Congregação da Faculdade de Direito testemunhar-lhe, agradecida, o alto aprêço em que o tem e proclamá-lo, solenemente, mestre entre os mestres".

Após êsse discurso, o Professor Alvino Lima, em nome da Congregação, entregou ao Professor Waldemar Ferreira. o título de "Professor Emérito". 
Agradecendo a homenagem que lhe era assim prestada, o Professor Waldemar Ferreira pediu ao Professor Alvino Lima que recebesse, como deferência especial à Egregia Congregação, o exemplar, que no momento lhe entregou, do quarto tômo, que naquêle mesmo dia saía à publicidade, da sua História do Direito Brasileiro, em que enfeixara as últimas lições dessa disciplina no Curso de Doutorado, e passou a proferir seu discurso de agradecimento.

\section{Oração do professor Waldemar Ferreira.}

"Revela-me esta solenidade, na aparente simplicidade litúrgica que a engalana, instante impregnado de singular sugestividade.

Não o dissimulo, antes lealmente o proclamo. Estou a exaltá-lo em meu fôro íntimo, desde que o antevi e me achei a acariciá-lo mentalmente para pasto de minha pobre vaidade e a ruminar as palavras que ora pronuncio, temente da emoção, que certamente me tomaria e em verdade agora me domina.

Sou, como quantos vivem em perene elevação de espírito, naturalmente emotivo; e creio mesmo seja êsse o atributo marcante de minha personalidade. Haverá quem o ponha em dúvida, que não tentarei desfazer. Deveria para isso tocar em problema de ordem psico-analítica, que deixo esvair-se em reticências, mas poderá um dia quiçá resolver-se, se eu lograr a fortuna, que não está ao alcance de minha vontade, de sobreviver a esta grã homenagem, com que estou a ser sagrado ao atingir a cumiada da minha carreira universitária.

São os fados mais caprichosos que a imaginação, a fiandeira de sonhos que dificilmente se convertem em realidade; e os meus bons fados, impelidos pela fôrça divina que me há propiciado muito mais do que fiz por merecer, bem-fazejamente me surpreendem nesta assentada. Como 
vos sou grato, senhores professôres e meus eminentissimos colegas, pela parte que nisso tomastes!

Não alimentastes, outorgando-me o título que me reaproxima desta escola mais que ilustre e veneranda, quando o tempo traiçoeiramente, de conluio com a lei, dela me afasta; não nutristes o propósito intencional de que êle me viesse pelas mãos amigas do professor Alvino Lina, meu velho companheiro de bancos acadêmicos, comigo e com o professor Sampaio Dória bacharelado na turma de 1908, e que eventualmente se acha, como vice-diretor, a presidir a esta sessão congregacional.

Sensibiliza-me esta coincidência. Por mercê dela e conivência da saudade, a impenitente convoladora do passado em presente, eu como que me transporto para os dias idos, em quê, provincianos tímidos nas atitudes, premidos de nossa pobreza de recursos, mas audazes na confiança em nós mesmos, nos encontramos nas velhas arcadas, que mais tarde me coube demolir e restaurar, conservando o timbre da tradição que lhes empresta o tono de eternidade, a ouvir Pedro Lessa, como sábio, filosofar sôbre o Direito, e Reynaldo Porchat, como expositor vivaz e eloquente, doutrinar Direito Romano.

Num lance de memória revejo aquêles dias, mas na revisão me detenho e, grato pela recordação consoladora, bemdigo êste instante em que podemos e devemos, nós dois, levantar as mãos bem ao alto, satisfeitos de havermos realizado as esperanças naquele tempo mimadas!

Se as mãos que me entregaram o título de professor emérito são as de um antigo companheiro de aulas, o verbo, que me exprimiu o sentimento dos professôres eminentíssimos, é o de antigo discípulo, dos primeiros aos quais lecionei o jus mercatorum. Não foi isso nesta casa. Foi na Universidade de São Paulo, que em 1917 aqui fundou cientista insigne, cujo nome relembro como homenagem aos seus méritos e dignidade, Edúardo Guimarães, antevendo o crescimento de São Paulo, mas que não foi bem compreendido na época. 
Fechadas as portas daquela prematura Universidade de São Paulo, os seus alunos para esta se transferiram e aqui se formaram e dois dêles prestigiam a douta Congregação - os professôres Mário Mazagão e Hónorio Monteiro; e êste que por ela me diz, com a sinceridade de sua estima idêntica á minha para com êle, o significado desta mercê.

Dizei-me, vós que me ouvis, ainda que no mutismo recôndito de vosso pensamento, se estas confluências de imponderáveis não são de molde a enternecer-me e dificultar-me a manifestação de meu agradecimento pela honraria de que me ensoberbeço!

Como não há de ser assim? Qual o sentido do título que se me concede? Aos professôres catedráticos resignatários ou aposentados, diz a lei, "cujos serviços ao magistério forem considerados de excepcional relevância, será conferido pela Congregação o título de professor emérito, cabendo-lhe o "direito de realizar cursos livres, comparecer ás reuniões da Congregação, sem direito de voto, e fazer parte de comissões universitárias".

Ora, eu já me puz dentro de mim mesmo, em trabalho introspectivo de exame de minha carreira de professor; e o resultado apurado por minha consciência foi o de que nada realizei de excepcional senão apenas que dei ao meu posto o que, em verdade, eu lhe deveria dar, cumprindo exata e lealmente a missão, que disputei e me concedeu, com o beneplácido da douta Congregação, o govêrno de meu País. Desde que busquei o magistério universitário e o obtive, selei comigo mesmo o compromisso de dar-lhe quanto eu pudesse a fim de que eu dêle fruisse as vantagens decorrentes. Queria isso dizer que, para ensinar, eu primeiro teria que aprender, redobrando meus estudos, em amplitude e profundidade. Seria isso essencial para que eu pudesse ensinar, partindo do preconceito de que sòmente são claros na exposição ou no ensinamento os que de verdade conhecem as disciplinas que ministram.

Dificuldades certamente se me antolhariam; e eu teria que vencê-las. Primeiro, pela assiduidade no trabalho. 
Forma-se inequivocamente entre professôres e alunos contrato bilateral, de ensinamento por parte daquêles e de aprendizado por parte destes; e o Código Civil me dizia que, nos contratos bilaterais, nenhum dos contraentes, antes de cumprida a sua obrigação, pode exigir o implemento da do outro. Por isso cuịdei do exato cumprimento da minha. Depois, porque necessitam os professôres de autoridade moral a fim de merecer, senão a admiração, ao menos o respeito dos discípulos, de molde ao estabelecimento de atmosfera de equilíbrio ensejadora do entendimento recíproco. Êsse equilíbrio, confesso em público e razo, no instante em que entro neste ocaso do meu magistério, jamais se rompeu, nos meus trinta anos de cátedra. Faço esta confissão para gáudio meu por certo, mas para honra dos que, nesse largo trato de tempo, diante dela passaram. Digno de nota é isso porque nunca os cortejei á cata de popularidade, mas sòmente a todos tratei guiado por espírito de justiça que os igualasse no meu apreço.

Sabia eu de resto que não poucas críticas se levantavam contra o nosso professorado e era mister desmontá-las mais com fatos do que com palavras. Nesse sentido foi o meu esfôrço; mas não apenas o meu, senão de todos os professôres que nestas velhas arcadas vêm ministrando o ensino jurídico, cada um a seu modo, tentando, para sua eficiência, os processos, meios e práticas usados nas universidades estrangeiras.

Não há porém método algum que tenha a virtude de instilar conhecimentos jurídicos a quem não os queira adquirir. Não é fazendo brilhar, pela compressão agitada, os fundilhos nos bancos acadêmicos, mercê da inquietude provocada pela desatenção durante as aulas, que se aprende direito. Para que se desenvolva o senso jurídico dos estudantes, pelo exercício do raciocínio técnico na solução das controvérsias, é indispensável que êles sejam realmente estudantés e não apenas rapazes ou raparigas, (pois é consideravel agora os contingentes destas) matriculadas nos cursos jurídicos. A diferença entre uns e outros é sensivel. 
Que existe, por isso mesmo, um como que desajuste entre professôres e alunos, é evidente. Se êstes arguem contra aquêles a desídia de uns, o despreparo de ouíros, ou as exigências e rigores descabidos de outros mais; aquêles deploram sobretudo o desinterêsse dêstes pelas aulas, de que se mostram ouvintes aéreos e apressados, desafeitos ao estudo, eventuais ledores de imperfeitas apostilas nas proximidades dos exames que lhes dêem aprovação, ainda que em grau mínimo, para a conquista, ao cabo de cinco anos, de vistoso passaporte para o futuro.

Agrava-se essa situação ano a ano com o aumento considerável dos candidatos aos cursos jurídicos: é a invasão das massas que se verifica também neste setor, comprimindo, avassalando e quebrando o padrão do ensino. Não impede o desdobramento das aulas que elas mais se pareçam com comícios! Como, dessarte, criar laboratórios, seminários, debates de casos concretos ou de problemas doutrinários, que requerem ambiente de serenidade e de cultura, para que benéficos sejam os resultados?

Dever-se-á desanimar e dar por falido o ensino juridico? Não!!! Muito haverá que fazer e modificar, ao menos para que, da massa dos matriculados, sobrenadem os estudantes de verdade, dotados de cultura humanística, inteligentes, lúcidos e aptos para o aprendizado jurídico. Dêstes, e sempre foi assim, sairão os homens insignes que tomarão sôbre si as responsabilidades pelo engrandecimento da Nação; e os juristas que empunharão, substituindo-nos, as tochas sagradas que, nestas arcadas, uma geração passa á que lhe sucede, fazendo a caminhada da eternidade. E a nossa velha e mais que centenária Faculdade de Direito prosseguirá na sua faina gloriosa e fecunda.

Disso estou eu convicto e seguro. Conheço-a bem. Sei quais são as fontes de sua grandeza e do seu prestigio se acham na beleza de seu passado e de sua tradição renovadora, que a coloca na sua situação vanguardeira em todos os tempos. E' que ela, na sua velhice, é sempre nova; e é 
a mesma na fôrça de mocidade, que a anima e aviventa, no suceder das gerações. Eis porque eu creio nela, como na aurora redentora que o sol, o magnânimo, faz desabrochar nos horizontes, todos os dias, a despeito das nuvens e brumas que lhe tornem cinzenta e plúmbea ás vêzes as cores majestosas que transitòriamente se eclipsam, mas não se apagam definitivamente. Creio nela porque não sou desiludido.

Deixando, em paga de muito ter vivido, as cátedras, que nela ocupei, não alimento nenhuma amargura. Não perdi o cajado dos que avançam no tempo. As armas dos dessa estirpe são, no dizer de CícEro, a virtude as letras. Cultivadas em qualquer idade, elas fornecem, mesmo ao fim de vida longa, frutos maravilhosos, pois a consciência de vida passada na honestidade e a memória de grande número de boas ações constituem fonte incessante de alegria.

Assegurando-me vós, senhores professôres e meus emjnentes colegas, com o título que me conferis, que os meus serviços ao magistério foram de excepcional relevância, é evidente que pratiquei grande número de boas ações; reiterando vós, meus antigos e últimos discípulos, êsse mesmo asserto - aumentais a minha alegria de tal modo que eu não sei se basta dizer-vos o meu reconhecimento num muito obrigado! vulgar, mas sincero!

Amen!

\section{A medalha Teixeira de Freitas ao Professor Waldemar Ferreira.}

Aprovou o Conselho Superior do Instituto dos Advogados Brasileiros, do Rio de Janeiro, a seguinte proposta apresentada pelo seu antigo presidente e ex-juiz, representante do Brasil, na Côrte Internacional de Haia, dr. Levi Carneiro: 


\section{Proposta}

“O sr. dr. Waldemar Martins Ferreira encerrou, há pouco, por jubilação compulsória motivada pela idade, sua atividade de professor catedrático da Faculdade de Direito da Universidade de São Paulo, onde, durante cerca de 30 anos, regeu, com a maior competência, a cátedra de Direito Comercial. Ao mesmo tempo, a partir de 1919 até agora, publicou, especialmente sôbre essa matéria, numerosas e notáveis obras de merecimento - comentários de jurisprudência, pareceres, análise e crítica das instituições, histórico e comentário da legislação. Pode resumir-se o valor de seu imenso e fecundo labor, nesse setor, dizendo que êle recebeu, e avultou, a sucessão de J. X. Carvalho de MenDONÇA.

Exilado do País, levou á alta cátedra da Universidade de Lisboa sua palavra clara e erudita, traçando As Diretrizes do Direito Mercantil Brasileiro.

Deputado federal, investido na presidência da Comissão de Constituição e Justiça da Câmara dos Deputados, seus estudos se estenderam a outros setores jurídicos, quer de Direito Privado quer de Direito Público - sempre com grande autoridade, inexcedível operosidade, profunda e extensa cultura jurídica. Da sua atuação, nesse pôsto eminente, que êle prestigiou, guardam memória indelével quantos a acompanharam; dela sobrevivem documentos imperecíveis nos pareceres que emitiu, alguns dos quais transformados em livros valiosos - como os que tratam dos ef eitos civis do casamento religioso, do direito judiciário do trabalho, do compromisso de venda de imóveis.

Ainda mais numerosos, são os pareceres que tem emitido, por solicitação dos interessados, em quase tôdas as principais controvérsias judiciárias do importantíssimo fôro de São Paulo. Paralelamente, exerceu sempre a advocacia.

Consagrou volumes, cujas edições e reedições se têm sucedido, a certos problemas particulares - como os das falências, do conhecimento do transporte ferroviário, das 
debentures. Publicou três volumes de um grandioso Tratado, que depois refundiu, elaborando as Instituições de Direito Comercial, de que já apareceram cinco volumes. Por último, tendo escrito a História da própria Faculdade de São Paulo, também escreveu a História do Direito Brasileiro, em três volumes, e a História do Direito Constitucional Brasileiro em um volume, ambas provenientes de suas aulas no Curso do Doutorado da mesma Faculdade de São Paulo.

Tôda essa vasta obra erudita e conscienciosa enche uns 50 volumes (vide Revista da Faculdade de Direito de S. Paulo, vol. XLV, pags. 31 a 104).

A de nenhum outro jurista brasileiro vivo será mais numerosa e extensa, mais benemérita e valiosa. Nenhuma terá prestado mais relevantes serviços á difusão e ao fortalecimento da cultura jurídica nacional. Raros se poderão comparar-lhe.

Parece, pois, em todos os pontos de vista, justo e oportuno que o Instituto dos Advogados Brasileiros confira ao sr. professor dr. Waldemar Ferreira a mais alta homenagem que pode prestar - outorgando-lhe a medalha de bronze Teixeira de Freitas, em reconhecimento "de serviços prestados á cultura jurídica do País".

E' o que proponho ao egrégio Conselho Superior.

Rio, 20 de março de 1956. - (a). Levi Carneiro. 